\title{
Intercomparison of intense cyclogenesis events over the Mediterranean basin based on baroclinic and diabatic influences
}

\author{
Ll. Fita, R. Romero, and C. Ramis \\ Grup de Meteorologia, Universitat de les Illes Balears, Mallorca, Spain \\ Received: 14 October 2005 - Revised: 30 January 2006 - Accepted: 14 February 2006 - Published: 11 May 2006
}

\begin{abstract}
A large number of high impact cyclones all over the Mediterranean basin have been reported on the data base of the MEDEX project (http://medex.inm.uib.es). A numerical study on the impacts and interactions of baroclinic and diabatic factors is carried out through a PV-based system of prognostic equations for 11 intense MEDEX cyclone episodes occurred in different zones of the basin (Western, Central and Eastern Mediterranean). The main aim of the study is to investigate the possible similarities and differences among the selected cases of the relative weight of the considered cyclogenetic factors on the cyclone evolutions as function of cyclone type and geographical area. A crucial role of the baroclinicity over the Mediterranean zone is obtained in most of the cases. A certain distinction can be also established in terms of the cyclogenesis areas (Africa, Mediterranean Sea, and Alpine region), and between westcentral and eastern Mediterranean basins. It is generally observed that the considered baroclinic and diabatic factors cooperate most strongly for the cyclone deepening process when the disturbance reaches the Mediterranean sea.
\end{abstract}

\section{Introduction}

The Mediterranean basin is well known as one of the most cyclogenetic zones of the world. A significant number of climatologies have been done, showing the main characteristics of the cyclones, trajectories and most cyclogenetic regions of the basin (e.g. Campins et al. (2000)). In this study a "dynamical" climatology of eleven Mediterranean cyclones is presented. As dynamical aspects, some evolving features of the atmosphere that are involved and related to the cyclone's evolution are considered: The upper level $\mathrm{PV}$ anomaly (PVp hereafter) associated to the undulating tropopause (PVp above $700 \mathrm{hPa}$, with a relative humidity (RH) less than 70\%), the low level PV anomaly (PVp un- der $700 \mathrm{hPa}$, drier than $70 \%$ together with surface thermal anomalies (Bretherton, 1966)) and the diabatically induced PVp (PVp below $500 \mathrm{hPa}$, with humidity higher than $70 \%$ ). The inclusion in the study of diabatically induced PVp aims to isolate the effects associated with latent heat release in the cyclone cloudy structure. The thermal anomaly induced by massive water vapor condensation at mid-upper tropospheric levels enhances the static stability above and this is reflected as a distinct PV positive anomaly (Hoskins et al., 1985).

The 11 selected cyclones have been chosen from the MEDEX data base. This data base has been constructed from the contributions of different National Weather Services, research institutes and universities of the entire Mediterranean basin. The cyclones have been classified in terms of their social impact. These 11 cases (see Table 1) have been chosen from the most severe MEDEX group, usually involving deep cyclogenesis. These cases have been selected trying to encompass all the Mediterranean basin.

The dynamical study is based on solving the geopotential height tendency due to the different factors using the prognostic system of equations proposed by Davis and Emanuel (1991). Via this PV-based set of prognostic equations, the impact of each PV anomaly could be studied by switching on and off those anomalies in the atmospheric state and combining the results for the height tendency using the Factor Separation technique (Stein and Albert, 1993). Both the individual effects as well as their mutual interactions could be properly isolated with such methodology. Section 2 provide a short description of each case. Section 3 and 4 provide details on the methodology and Sect. 5 the main results and conclusions. 
Table 1. Table of the 11 selected cases. 1st col. indicates the title of the case ([DD]/[MM]/[YY]), 2on col. indicates the date of cyclone's mature state $([\mathrm{DD}] /[\mathrm{MM}] /[\mathrm{YY}])$ and $P_{\min }$ indicates minimum central pressure value $(\mathrm{hPa})$ and corresponding time according to ECMWF analysis. 3rd col. indicates the Mediterranean region where the cyclone evolved. 4th col. indicates cyclogenesis area.

\begin{tabular}{llcc}
\hline Case & maximum depth $\left(P_{\text {min }}\right)$ & Med. region & cyclone type \\
\hline $6-9 / 10 / 96$ & $7 / 1006(1003.6)$ & Central & Alpine lee \\
$16-18 / 03 / 98$ & $16 / 0300(984.1)$ & Eastern & African \\
$6-9 / 11 / 99$ & $7 / 1106(997.5)$ & Central & Alpine lee \\
$13-16 / 10 / 00$ & $15 / 1006(1001.9)$ & Western & African \\
$9-13 / 11 / 01$ & $11 / 1100(993.0)$ & Western & African \\
$23-24 / 11 / 01$ & $25 / 1112(989.3)$ & Eastern & Alpine lee \\
$3-4 / 12 / 01$ & $2 / 1212(997.7)$ & Eastern & Maritime \\
$14-15 / 12 / 01$ & $14 / 1200(1005.5)$ & Western & Maritime \\
$6-8 / 05 / 02$ & $7 / 0500(993.0)$ & Western & African \\
$13-14 / 07 / 02$ & $14 / 0700(1002.8)$ & Central & African \\
$8-10 / 10 / 02$ & $12 / 1006(997.8)$ & Western-Central & Maritime \\
\hline
\end{tabular}

\section{Description of cases}

Each case represents a different cyclone evolution over the Mediterranean basin. Their major characteristics are briefly described (see MEDEX database for more details at http: //medex.inm.uib.es) as well as depicted trajectories (right panel) in Figs. 1 to 11:

1. 6-9/10/96: An upper level cut-off evolved into the Mediterranean basin, from which the cyclone was created off the coastal line of Algiers. The eastward progression of the cut-off produced an evolution of the cyclone over the sea toward the east.

2. 16-18/03/98: A north African thermal low was developed to the south of the Atlas mountains. Through the interaction with an upper level trough, the cyclone moved over the Sahara desert and entered into the Mediterranean Sea across the Egyptian coast when it reached the mature state.

3. 6-9/11/99: This cyclone can be considered as an Alpine-lee cyclogenesis (Buzzi and Tibaldi, 1978). The mature cyclone moved Southeastward over the Mediterranean Sea.

4. 13-16/10/00: A thermal low over African plateau interacted with an upper level trough. The cyclone moved toward the Mediterranean Sea over Algiers following a northward trajectory. When the cyclone reached the sea, the low reached the mature state.

5. 9-13/11/01: This case is very similar to the previous one $(13-16 / 10 / 00)$. In this case the cyclone is deeper and stronger.

6. 23-24/11/01: The cyclone presented two phases. An Alpine-lee cyclone moved from the Golf of Genoa following the Adriatic Sea forced by an upper level trough.
Meanwhile the upper level trough became a cut-off, the cyclone moved then northeastward and reached the Black Sea where it attained its mature state.

7. 3-4/12/01: A low latitude upper level disturbance induced a cyclone over the Cyprus island region. The cyclone stayed on the region during all its life cycle.

8. 14-15/12/01: An upper level cut-off moved southwestward from the Central Europe region. As a result, a cyclone was developed on the lee of the Alps mountains.

9. 6-8/05/02: Another case similar to $16-18 / 03 / 98$ where the interaction between an African thermal low and an upper level trough induced a cyclone which reached the mature state when it entered in the Mediterranean basin in front of the coast of Algeria.

10. 13-14/07/02: A thermal North African cyclone interacted with an upper level trough. In this case the cyclone moved into the Mediterranean basin across the coastal region of Tunis, and moved northward to Balkan countries.

11. 8-10/10/02: An Atlantic cyclone moved southeastward owing to the southeastward movement of an upper level trough. The cyclone crossed the north of Spain and moved eastward along the Mediterranean Sea reaching Greece.

\section{PV-based prognostic equations}

The closed system of PV-based prognostic equations (Davis and Emanuel, 1991) is used to solve the geopotential height tendency equation. Geopotential height $(\phi)$ and stream function $(\psi)$ are first obtained from a given PV distribution $(q)$ via the non-linear $P V$ inversion technique (explained also in Davis and Emanuel (1991)). The geopotential height, stream 
function and PV tendencies $\left(\phi^{t}, \psi^{t}, q^{t}\right.$, respectively) can be calculated after applying the tendency operator to the Charney nonlinear balance equation (Eq. 1), Ertel's $P V$ definition (Eq. 2) and the Ertel's PV conservation equation, under the frictionless and diabatic form (Eq. 3).

$$
\begin{aligned}
\nabla^{2} \phi^{t} & =\nabla \cdot f \nabla \psi^{t}+2 m^{2}\left[\frac{\partial^{2} \psi^{t}}{\partial x^{2}} \frac{\partial^{2} \psi}{\partial y^{2}}+\frac{\partial^{2} \psi}{\partial x^{2}} \frac{\partial^{2} \psi^{t}}{\partial y^{2}}\right. \\
& \left.-2 \frac{\partial^{2} \psi}{\partial x \partial y} \frac{\partial^{2} \psi^{t}}{\partial x \partial y}\right] \\
q^{t} & =\frac{g \kappa \pi}{p}\left[\left(f+m^{2} \nabla^{2} \psi\right) \frac{\partial^{2} \phi^{t}}{\partial \pi^{2}}+m^{2} \frac{\partial^{2} \phi}{\partial \pi^{2}} \nabla^{2} \psi^{t}\right. \\
- & m^{2}\left(\frac{\partial^{2} \psi^{t}}{\partial x \partial \pi} \frac{\partial^{2} \phi}{\partial x \partial \pi}+\frac{\partial^{2} \psi}{\partial x \partial \pi} \frac{\partial^{2} \phi^{t}}{\partial x \partial \pi}\right. \\
+ & \left.\left.\frac{\partial^{2} \psi^{t}}{\partial y \partial \pi} \frac{\partial^{2} \phi}{\partial y \partial \pi}+\frac{\partial^{2} \psi}{\partial y \partial \pi} \frac{\partial^{2} \phi^{t}}{\partial y \partial \pi}\right)\right] \\
q^{t}= & -m\left(\boldsymbol{v}_{\psi}+\boldsymbol{v}_{\chi}\right) \cdot \nabla q-\omega^{*} \frac{\partial q}{\partial \pi} \\
+ & \overbrace{\frac{\mathcal{D} \mathcal{I} \mathcal{A} \mathcal{B} \mathcal{I}}{p}\left[\eta \cdot \nabla\left(\frac{d \theta}{d t}\right)+\nabla \theta \cdot \nabla \times \boldsymbol{F}\right]}
\end{aligned}
$$

The formulation of the horizontal wind is partitioned in non-divergent and irrotational parts according to equations 4 :

$$
\left\{\begin{array}{l}
\boldsymbol{v}_{\psi}=m \hat{k} \times \nabla \psi \\
\boldsymbol{v}_{\chi}=m \nabla \chi
\end{array}\right.
$$

In the above equations $m$ is the map factor, $\kappa=\frac{R_{d}}{C_{p}}$, and $\pi=C_{p}\left(\frac{p}{p_{0}}\right)^{\kappa}$ is the Exer function used as vertical coordinates in the formulation. From the omega equation (Eq. 5) the vertical velocity $\left(\omega^{*}=\frac{d \pi}{d t}=\frac{\kappa \pi}{p} \omega\right)$ can be solved:

$$
\begin{aligned}
& f \eta \frac{\partial}{\partial \pi}\left[\pi^{1-\frac{1}{\kappa}} \frac{\partial}{\partial \pi}\left(\pi^{\frac{1}{\kappa}-1} \omega^{*}\right)\right]+m^{2} \nabla^{2}\left(\frac{\partial^{2} \phi}{\partial \pi^{2}} \omega^{*}\right) \\
& -\quad m^{2} f \frac{\partial}{\partial \pi}\left(\frac{\partial \omega^{*}}{\partial x} \frac{\partial \psi}{\partial x \partial \pi}+\frac{\partial \omega^{*}}{\partial y} \frac{\partial \psi}{\partial y \partial \pi}\right) \\
& +\quad\left(f \frac{\partial \eta}{\partial \pi} \frac{\frac{1}{\kappa}-1}{\pi}-f \frac{\partial^{2} \eta}{\partial \pi^{2}}\right) \omega^{*} \\
& =\quad m^{3} \nabla^{2}\left[\left(\boldsymbol{v}_{\psi}+\boldsymbol{v}_{\chi}\right) \cdot \nabla \theta\right] \\
& +\quad m f \frac{\partial}{\partial \pi}\left[\left(\boldsymbol{v}_{\psi}+\boldsymbol{v}_{\chi}\right) \cdot \nabla \eta\right]-m^{2} \nabla f \cdot \nabla\left(\frac{\partial \psi^{t}}{\partial \pi}\right) \\
& -\quad 2 m^{4} \frac{\partial}{\partial \pi}\left[\frac{\partial^{2} \psi^{t}}{\partial x^{2}} \frac{\partial^{2} \psi}{\partial y^{2}}+\frac{\partial^{2} \psi}{\partial x^{2}} \frac{\partial^{2} \psi^{t}}{\partial y^{2}}\right. \\
& \left.-\quad 2 \frac{\partial^{2} \psi}{\partial 10 \partial y} \frac{\partial^{2} \psi^{t}}{\partial x \partial y}\right]
\end{aligned}
$$

$$
+\overbrace{\nabla^{2}\left(\frac{d \theta}{d t}\right)}^{\mathcal{D I} \mathcal{A} \mathcal{B I I}}
$$

Finally with the continuity equation the system is closed (Eq. 6):

$$
m^{2} \nabla^{2} \chi+\pi^{1-\frac{1}{\kappa}} \frac{\partial}{\partial \pi}\left(\pi^{\frac{1}{\kappa}-1} \omega^{*}\right)=0
$$

Lateral homogeneous $\left(\phi^{t}=\psi^{t}=q^{t}=\omega^{*}=\chi=0\right)$ and Neumman top and bottom (Eq. 7) boundary conditions are used for the tendencies:

$$
\begin{aligned}
\frac{\partial \phi^{t}}{\partial \pi} & =f \frac{\partial \psi^{t}}{\partial \pi}=-\theta^{t} \\
& =-m\left(\boldsymbol{v}_{\psi}+\boldsymbol{v}_{\chi}\right) \cdot \nabla \theta-\omega^{*} \frac{\partial \theta}{\partial \pi}
\end{aligned}
$$

Zero vertical velocity on the top of the domain and topographic vertical velocity on the surface are imposed.

\section{Factor separation}

The role of the $3 \mathrm{PV}$ anomalies defined in the introduction can be studied by solving the previous system of equations for the geopotential height tendency (an indicator of cyclogenesis/cyclolisis processes) after switching off these anomalies in the starting PV distribution. Individual and synergistic effects during the live cycle of the cyclones using the Factor separation technique (Stein and Albert, 1993) will be isolated. This technique allows to obtain the individual effects and the mutual interactions of a set of different factors (in this study contributing to the total geopotential height tendency). In this case the following effects are isolated:

- E0: Effect of the Background flow

- E1: Effect of the Upper level PVp $(<700 \mathrm{hPa}$, $\mathrm{RH}<70 \%)$

- E2: Effect of the Low level PVp $(>700 \mathrm{hPa}, \mathrm{RH}<70 \%)$

- E3: Effect of the Diabatic PVp (>500hPa,RH $>70 \%)$

- Eij: Effect of the synergy Ei \& Ej

- E123: Effect of the synergy of the three anomalies

The study is focused on the effects of each factor on the most relevant total geopotential height tendency signal (at $925 \mathrm{hPa}$ ) that governs the cyclone evolution from its genesis to its decay. A spatial-average of the effects of each factor/interaction on the height tendency is depicted for each time-step and the results examined. Negative values indicate deepening and movement of the cyclone, whereas positive values would act to fill or slow the disturbance. The ECMWF $6 \mathrm{~h}$-analysis have been used as the numerical atmospheric field input. 

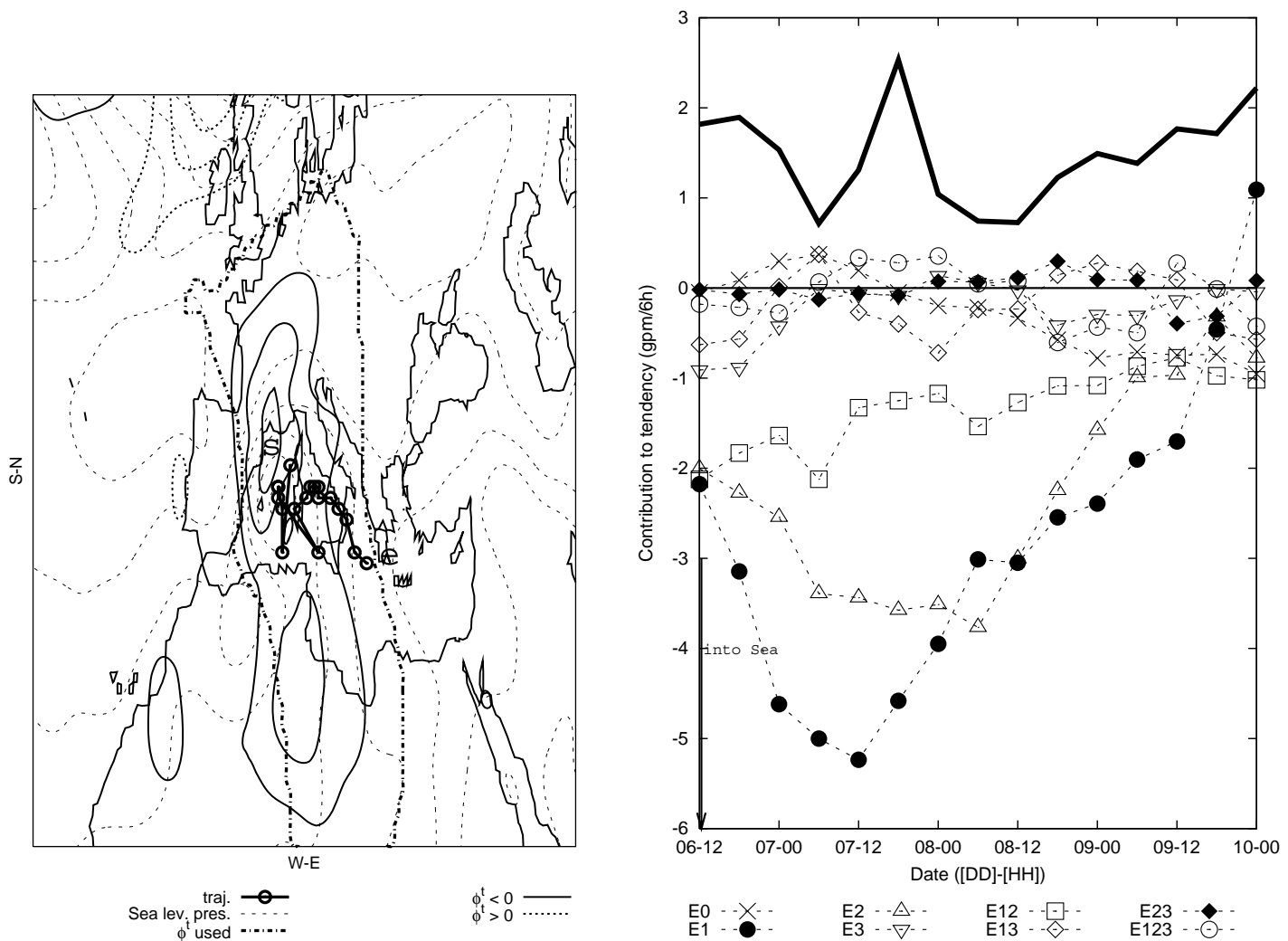

Fig. 1. "Alpine lee" \& Central Mediterranean case 6-9/10/96. On left panel: Cyclone trajectory (solid thick line with circles), $\phi^{t}$ at $925 \mathrm{hPa}$ (dashed line positive, solid line negative, every $10 \mathrm{gpm} / 6 \mathrm{~h}$ ), Sea level pressure (dot line, every $4 \mathrm{hPa}$ ) and geopotential height tendency signal used to compute the effects (thick dash-dot line) at mature cyclone time. Labels indicate starting (s) and ending (e) central cyclone position. Right panel: Evolution of the space-average tendency by each factor/interaction filtered with a three-step moving filter (dashed lines, and corresponding symbols as defined in bottom figure). Black arrows show when the cyclone reached/left the Sea. The cyclone central pressure evolution is shown as the solid thick upper line (no scale).

\section{Conclusions}

The results for the 11 Mediterranean cyclones are presented. A larger and deeper study should be done with more cases in order to obtain more general results, but the current approach attempts to incorporate cyclones of different geographical areas and dynamical evolution.

From Figs. 1 to 11 the results for each cyclone are shown. The results are generally case dependent with respect to the importance of the selected effects. However some conclusions can be emphasized: Generally the upper level PVp (effect E1) is the most relevant (showing the important role of the baroclinicity over the Mediterranean basin, like in 1314/7/02 and 14-15/12/01 cases). Most of the selected cases presented a significant upper level trough or cut-off during the cyclone evolution.

Low level PVp (E2) \& synergy E12 mainly play secondary roles (like in cases shown in Figs. 4, 5 and 11). This result depicts the importance of the role of the low level PV attributed to the thermal anomaly associated to the cyclone (in some cases related to the North African warm and dry plateau). The background flow (E0) is mainly responsible for the displacement of the disturbance (e.g. in Fig. 10 where this weak cyclone moved northward due to this factor). Western \& Central Mediterranean cyclones seem to be mainly dominated by PV anomalies E1, E2 and their synergy E12 (as is shown by Fig. 5). In contrast eastern Mediterranean cyclones show a non unique principal factor dependence. They are dominated by a variety of effects of distinct nature like E12, E1, E123 or E0 as it is shown in Figs. 2 and 6. This apparent regional characteristic of the Mediterranean cyclones could be attributed to the different origin of the cyclone. Of the selected cases the western and Central cases mainly were North African plateau or Alpine lee cyclones. However, the Eastern cyclones present different genesis zones and trajectories.

The effects related with the diabatically induced PVp (E3, E13 and E23) present the lowest contribution, even for the cyclones presenting high deepening process when reaching the sea (leading to mature state) like in Figs. 2 and 5. Note that the above effects are related with the role of diabaticallygenerated PV, not with the diabatic forcing itself as it is included in the right hand sides of Eqs. (3) and (5). Explicit consideration of these terms as new factors will be developed in a further step of the study. 

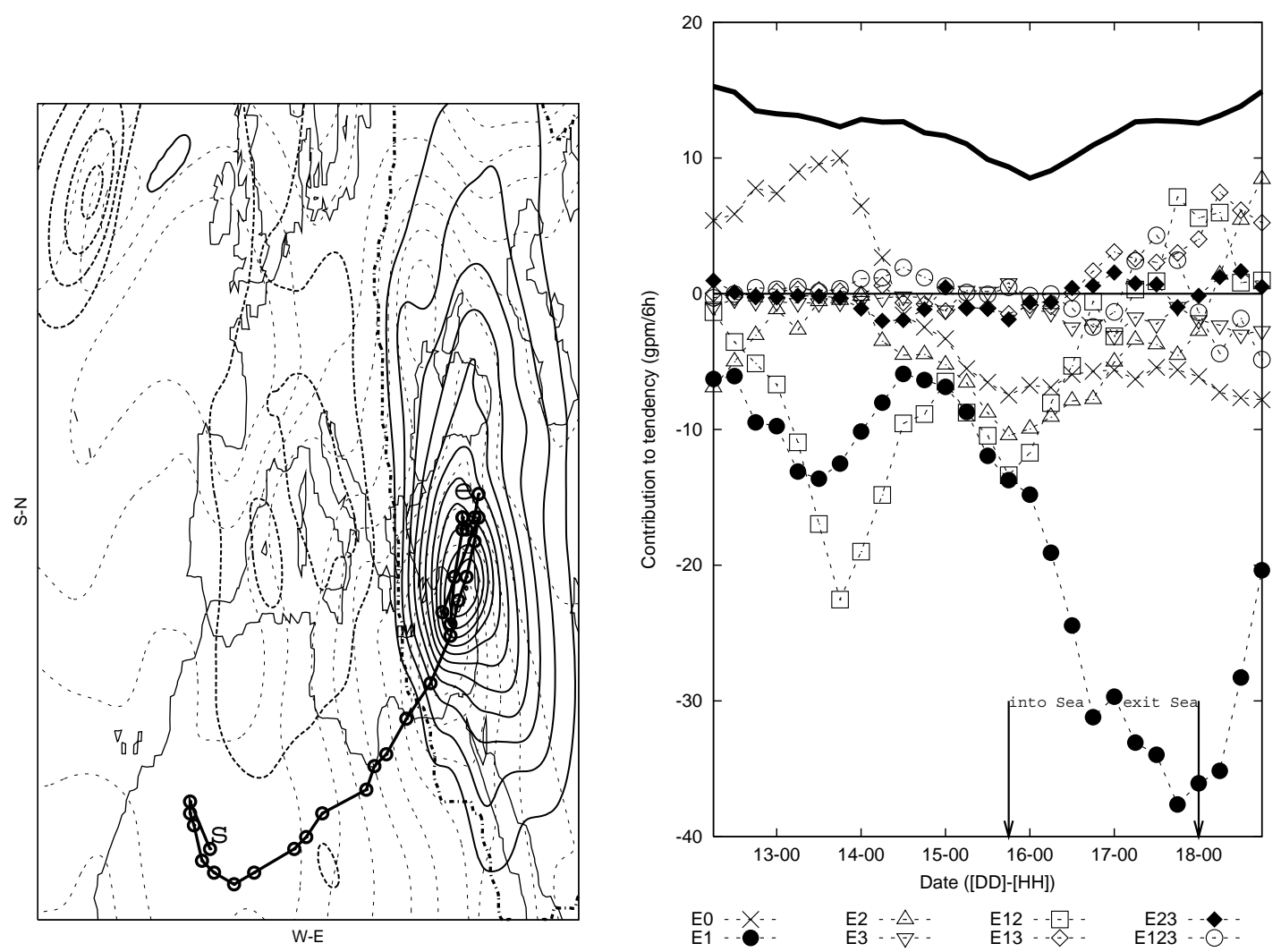

Fig. 2. As in Fig. 1 for "African" \& Eastern Med. case 16-18/03/98, but $\phi^{t}$ at $925 \mathrm{hPa}$ every $25 \mathrm{gpm} / 6 \mathrm{~h}$.
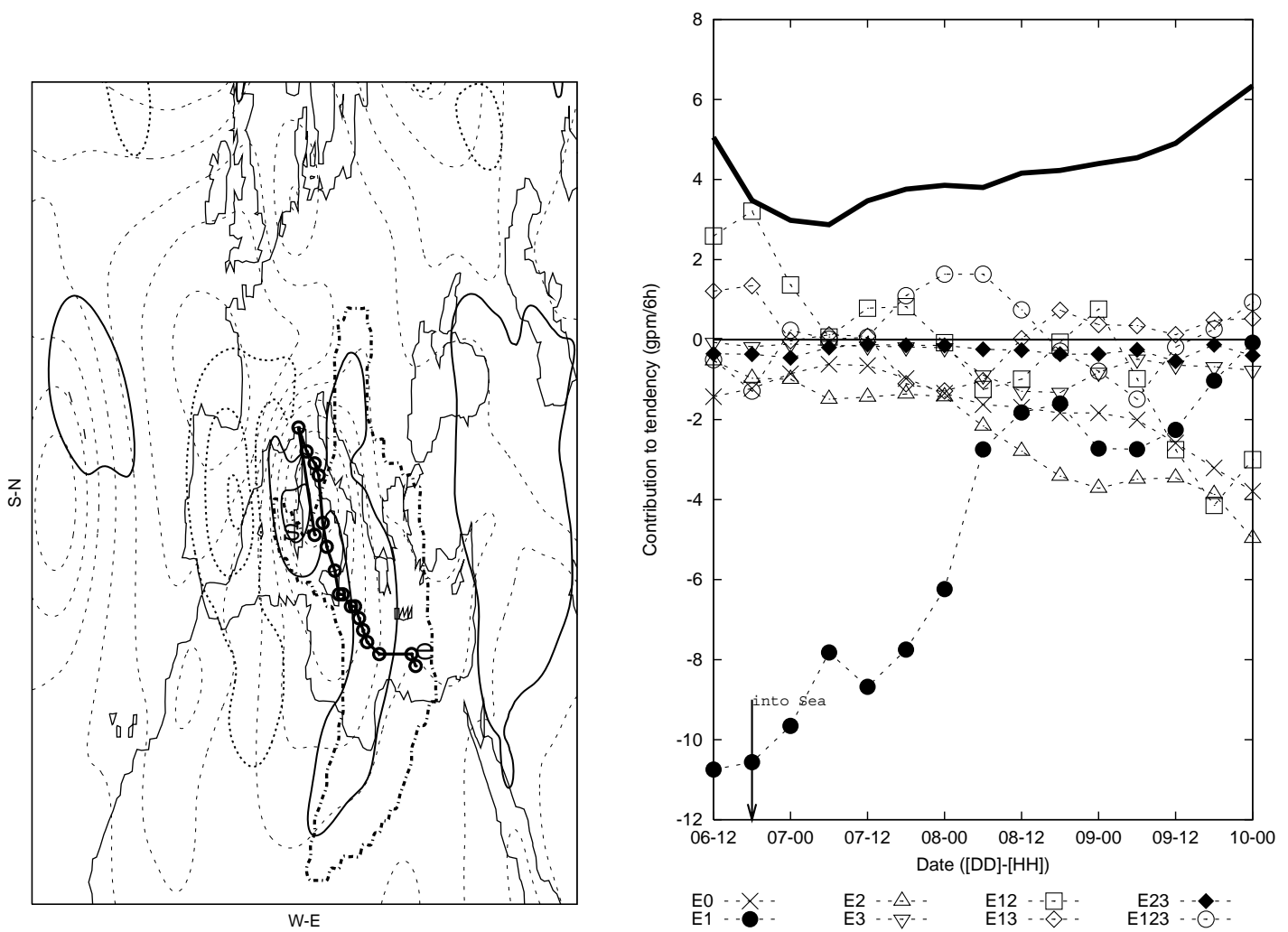

Fig. 3. As in Fig. 1 for "Alpine lee" \& Central Med. case 6-9/11/99 

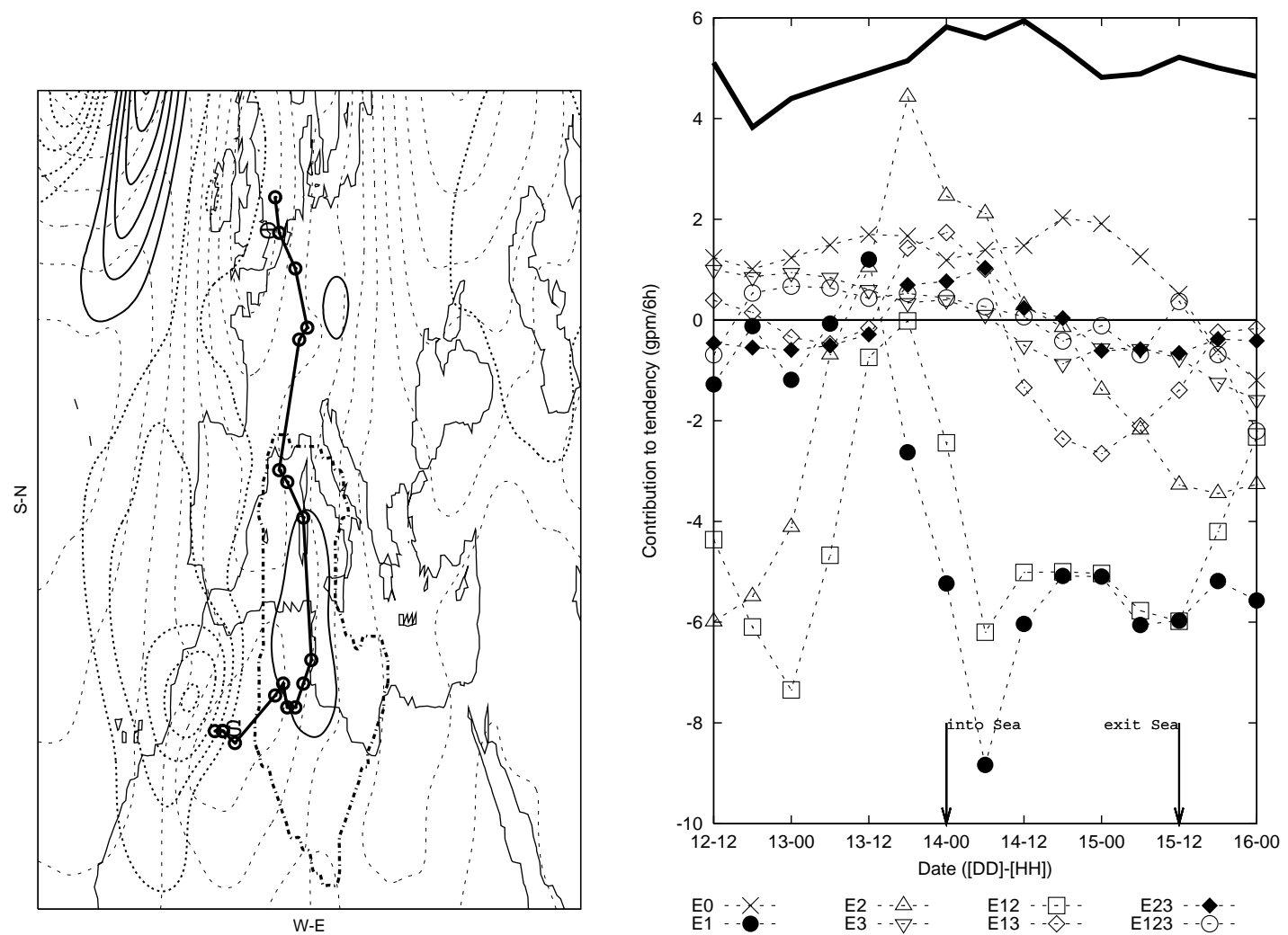

Fig. 4. As in Fig. 1 for "African" \& Western Med. case 13-16/10/00.
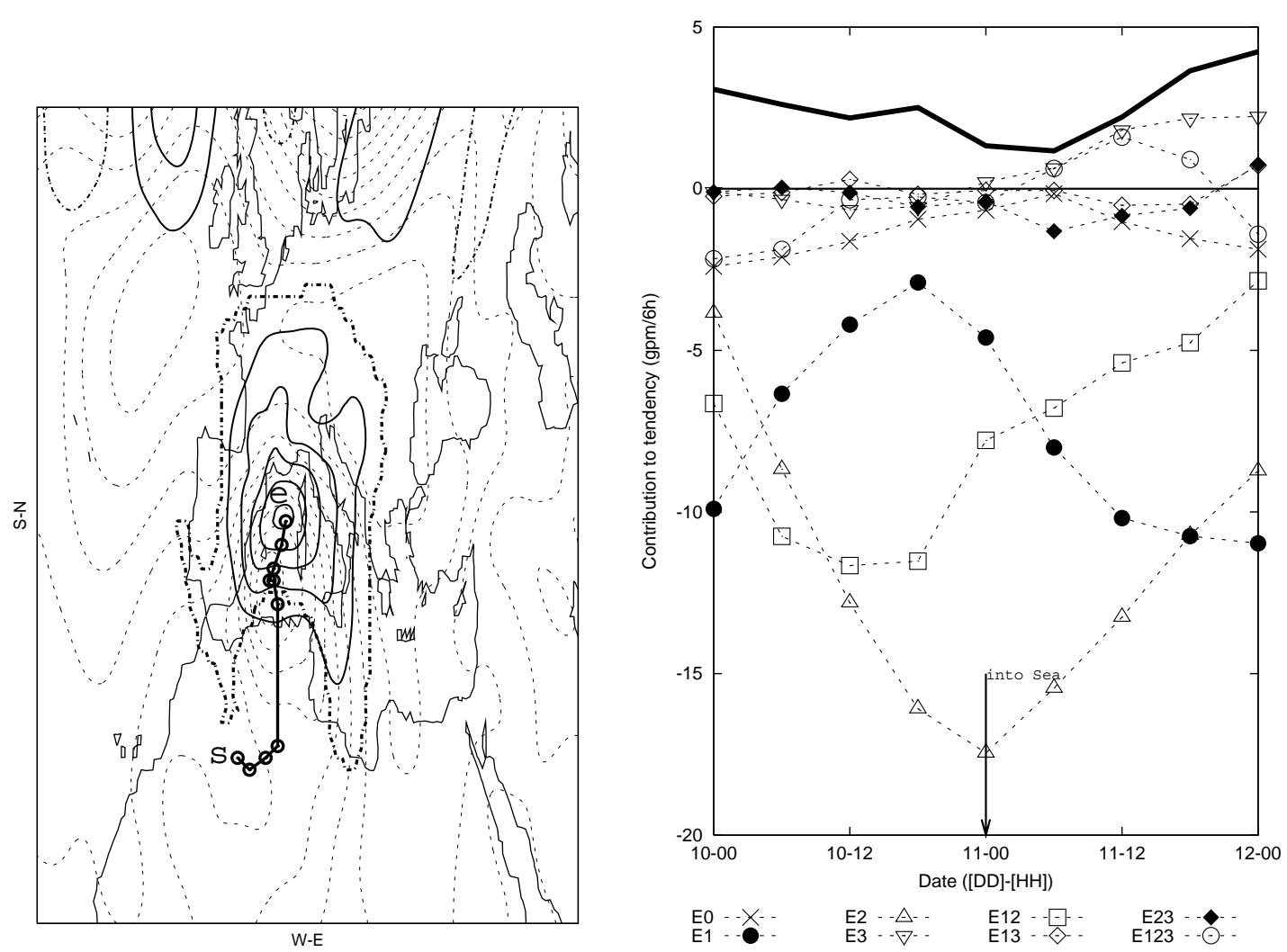

Fig. 5. As in Fig. 1 for "African" \& Western Med. case 9-13/11/01, but $\phi^{t}$ at $925 \mathrm{hPa}$ every $25 \mathrm{gpm} / 6 \mathrm{~h}$. 

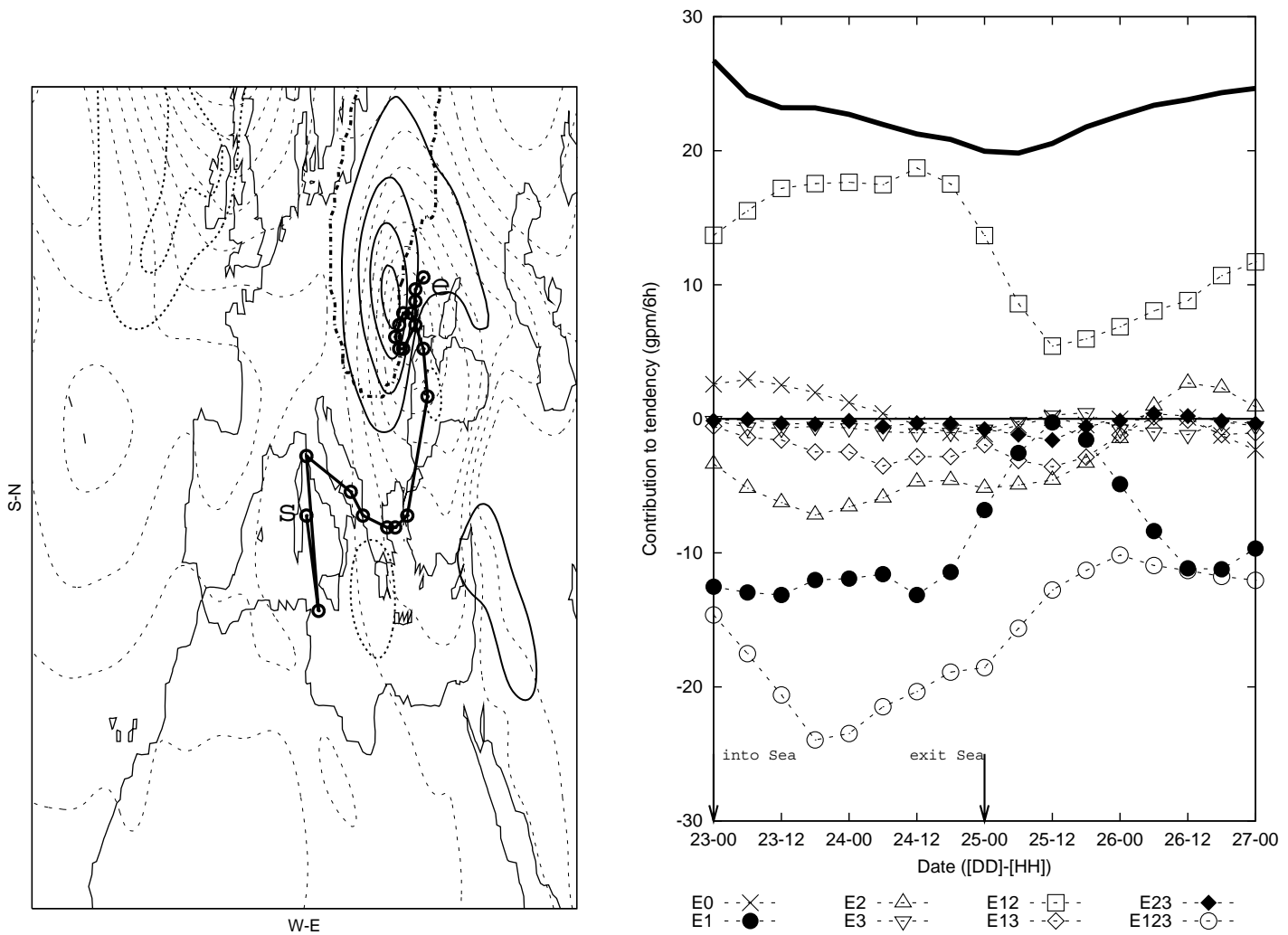

Fig. 6. As in Fig. 1 for "Alpine lee" \& Eastern Med. case 23-24/11/01, but $\phi^{t}$ at $925 \mathrm{hPa}$ every $25 \mathrm{gpm} / 6 \mathrm{~h}$.
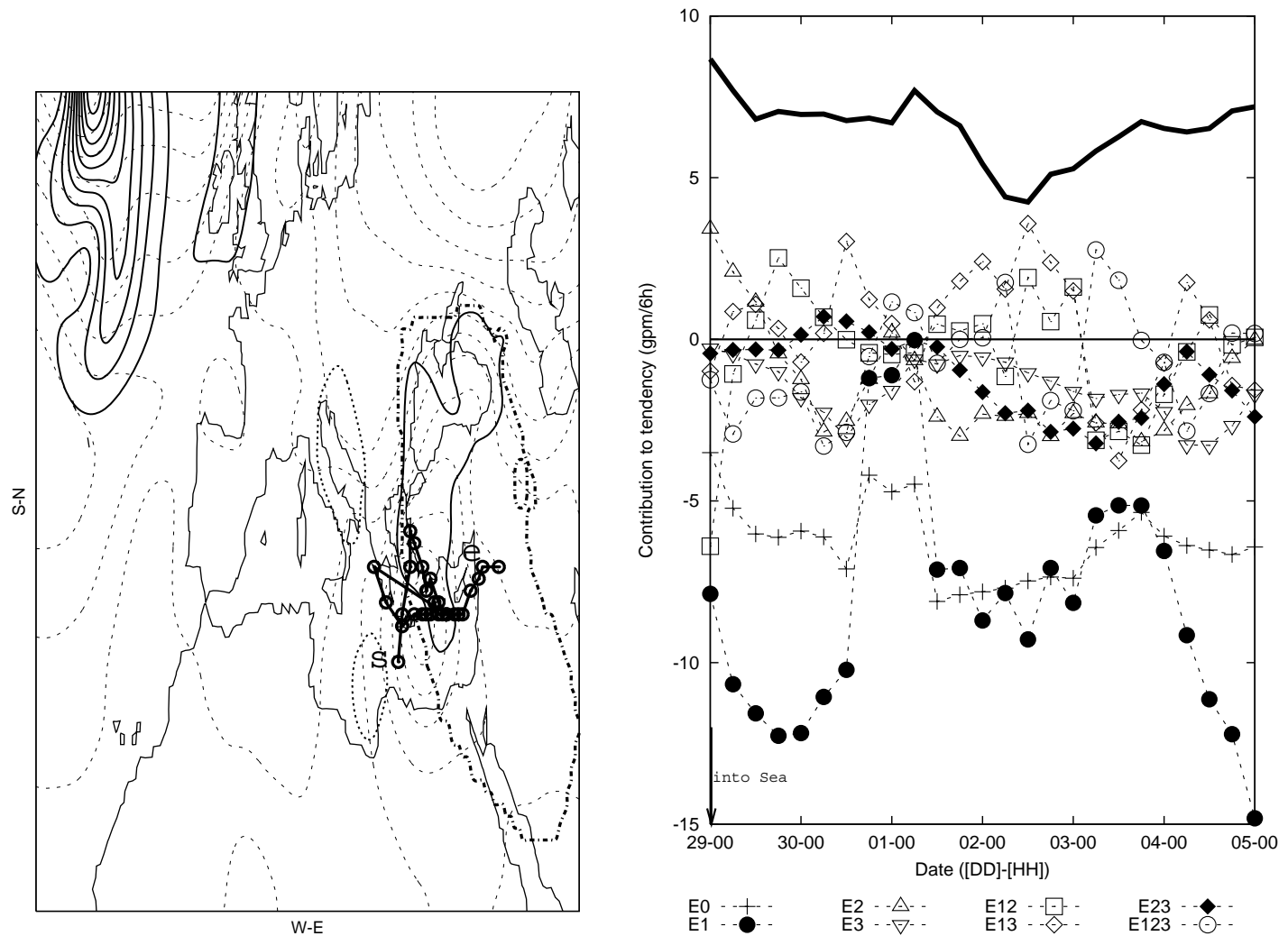

Fig. 7. As in Fig. 1 for "Maritime" \& Eastern Med. case 3-4/12/01, but $\phi^{t}$ at $925 \mathrm{hPa}$ every 25 gpm/6 h. 

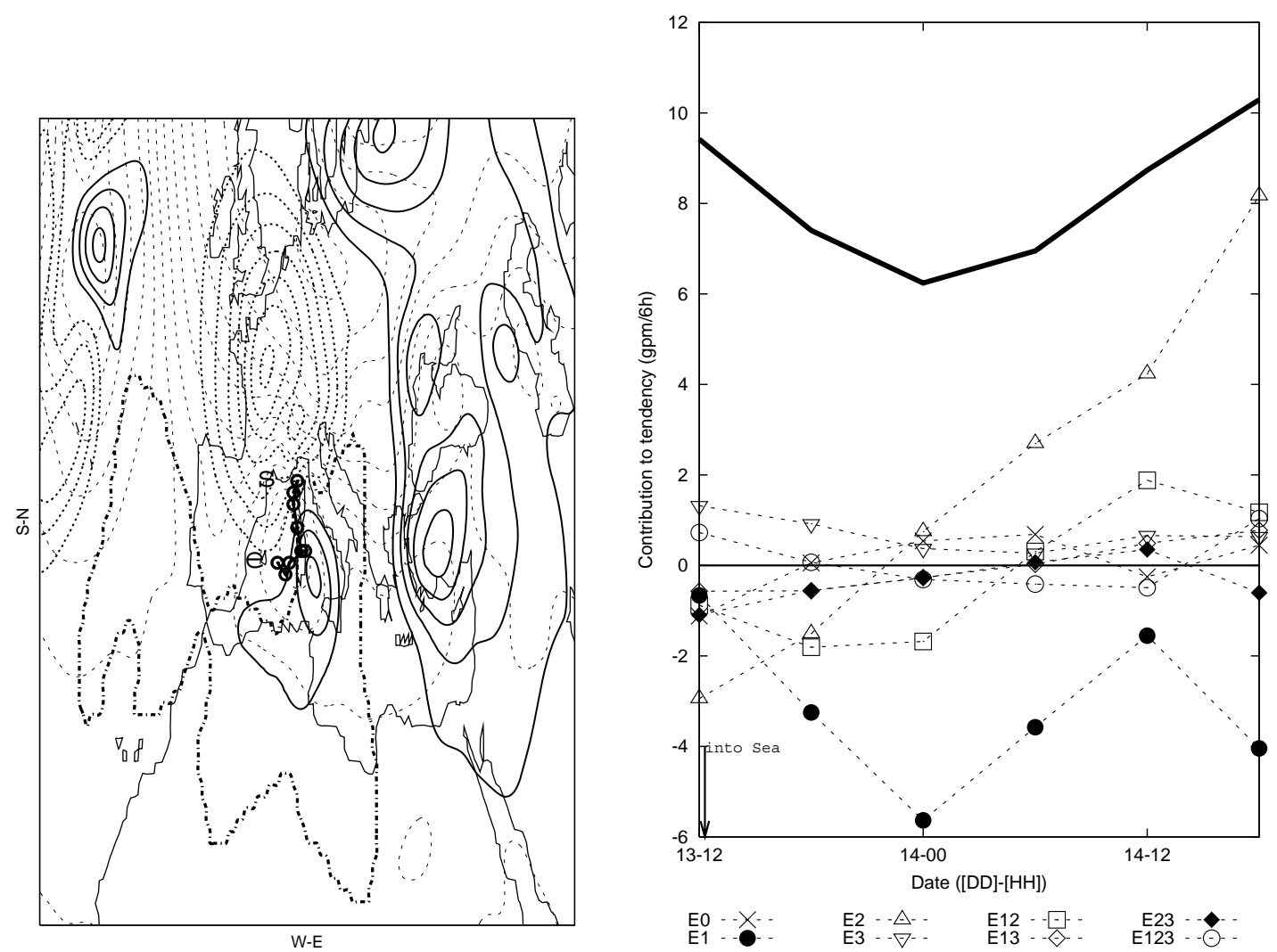

Fig. 8. As in Fig. 1 for "Maritime" \& Western Med. case 14-15/12/01.
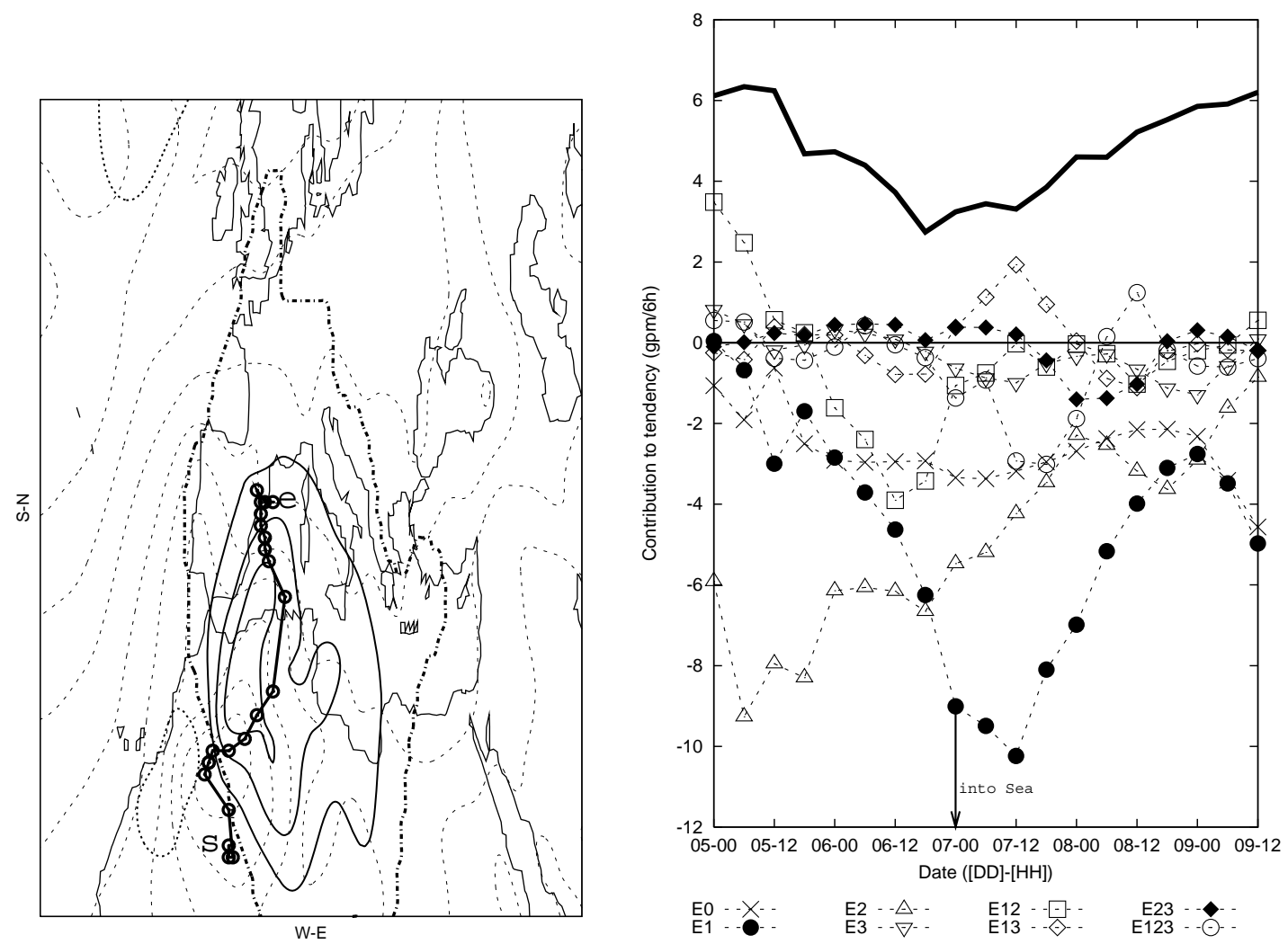

Fig. 9. As in figure 1 for "African" \& Western Med. case 6-8/05/02, but $\phi^{t}$ at $925 \mathrm{hPa}$ every $25 \mathrm{gpm} / 6 \mathrm{~h}$. 

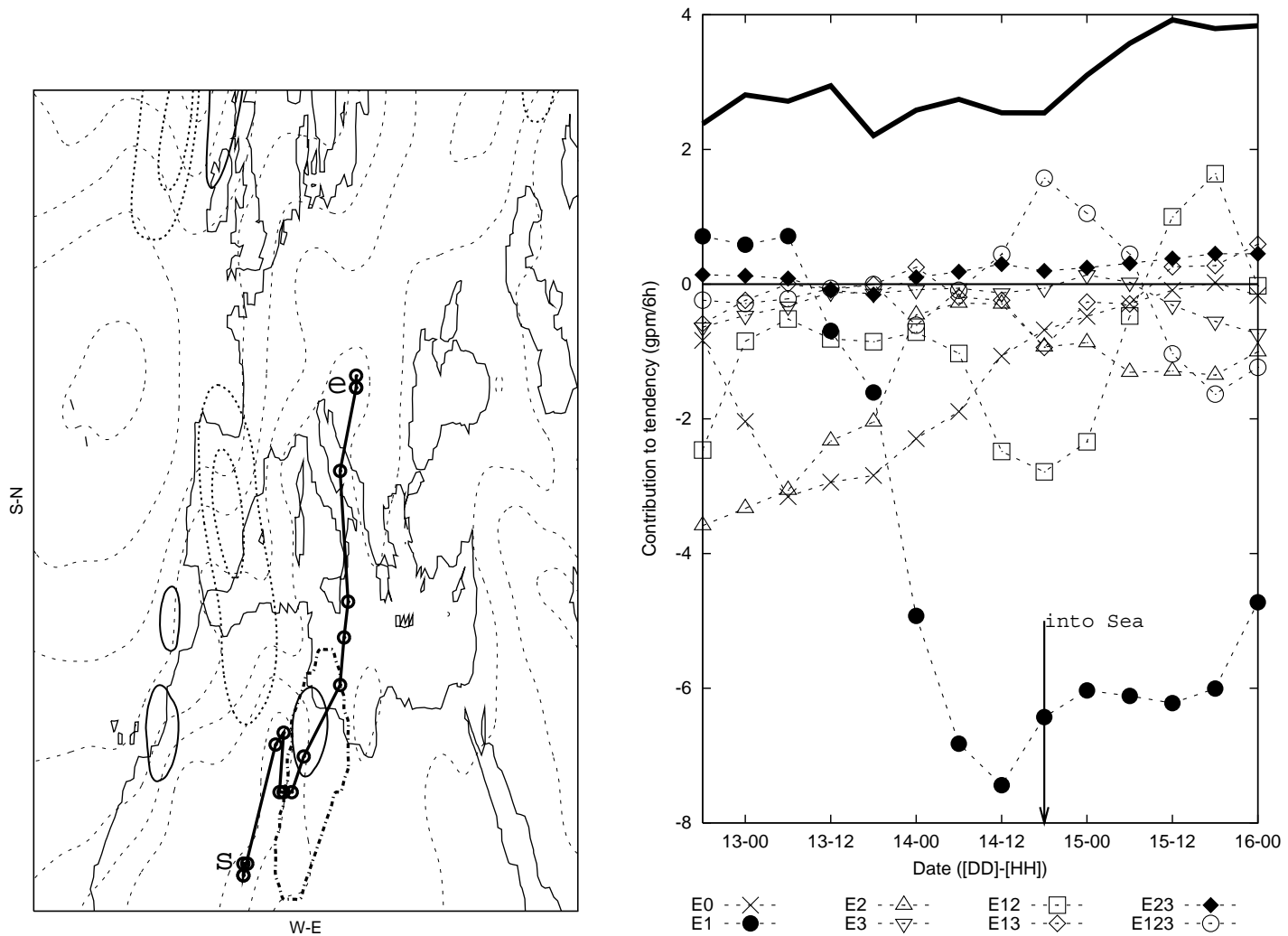

Fig. 10. As in Fig. 1 for "African" \& Central Med. case 13-14/07/02.
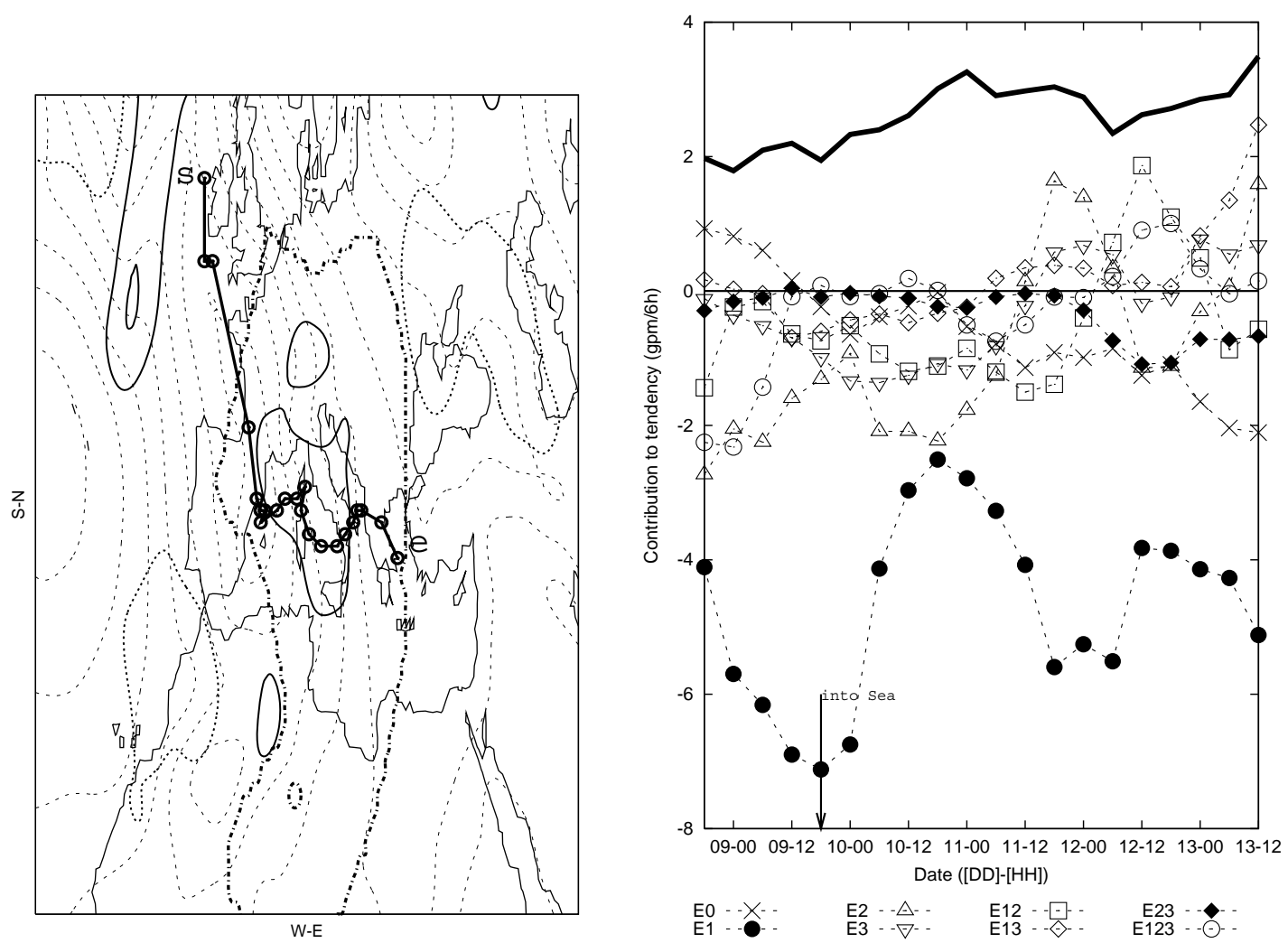

Fig. 11. As in Fig. 1 for "Maritime" \& W-Central Med. case 8-10/10/02, but $\phi^{t}$ at $925 \mathrm{hPa}$ every 25 gpm/6 h. 
Factors are often cyclogenetic and cyclolitic probably owing to the complex topographical configuration of the basin and other evolving interactions involved in baroclinic developments like: Upperlevel-low level interaction (Hoskins et al., 1985) (e.g. E2 and E12 change sign in 8-10/10/02 case owing to the change of vertical tilt of the disturbances), cyclone position relative to the orography and background flow (e.g. E0 became cyclogenetic since the cyclone moved over the Tunis planes on case 16-18/03/98).

"African" cyclones (like in Figs. 2 and 10) are mainly dominated by Upper level disturbances (factor E1) or the synergy E12. "Maritime" cyclones (shown in Figs. 7 or 11) seem to be dominated mainly by E1 and in lower proportion by the background flow (E0 effect). The selected "Alpine Lee" cyclones (like in Figs. 1 and 3) seem to present an initially strong role of the upper level tropopause disturbance (factor E1), with a second cyclogenetic phase dominated by E2 probably related to the induced PV banners of a lee cyclogenesis, and finally the maritime phase dominated by E2 probably due to the role of the moist processes. Finally it is sometimes obtained a compensation between large cyclogenetic and cyclolitic effects (e.g. E123 and E1 cyclogenetic effects are compensated by E12 and E0 on 23-24/11/01 case during the initial steps of the evolution of the cyclone)

Cyclogenesis events in the Mediterranean have often been classified attending to affected geographical zone, social impact, NWP performance and/or deepening rate (e.g. MEDEX database, see http://medex.inm.uib.es). In this work the emphasis is made on the role of evolving and interacting dynamical aspects of the synoptic-scale circulation as represented by PV anomalies, and it is hoped that the approach can be extended and refined to perform a dynamical climatology of deep cyclogenesis events in the Mediterranean basin. The results presented are not yet conclusive, but seem to indicate that some dynamical differences in Mediterranean cyclogenesis can be related to the nature and track location of the disturbance.
Acknowledgement. Support from MEDEX-IB/REN 2002-03482 project and PhD grant BES-2003-0696 (both from the Spanish "Ministerio de Eduación y Ciencia") are acknowledged.

Edited by: V. Kotroni and K. Lagouvardos

Reviewed by: anonymous referee

\section{References}

Bretherton, F. P.: Critical layer instability in baroclinic flows, Quart. J. R. Met. Soc., 92, 325-334, 1966.

Buzzi, A. and Tibaldi, S.: Cyclogenesis in the lee of Alps: A case study, Quart. J. R. Met. Soc., 104, 271-287, 1978.

Campins, J., Genovés, A., Jansà, A., Guijarro, J. A., and C., R.: A catalogue and a classification of surface cyclones for the western Mediterranean, Int. J. Climatol., 20, 969-984, 2000.

Davis, C. A. and Emanuel, K. A.: Potential vorticity diagnostics of cyclogenesis, Mon. Weat. Rew., 119, 1929-1953, 1991.

Hoskins, B. J., McIntyre, M. E., and W., R. A.: On the use and significance of isentropic potential vorticity maps, Quart. J. R. Meteo. Soc., 111, 877-946, 1985.

Stein, U. and Albert, P.: Factor Separation in Numerical Simulations, J. Atmos. Scien., 50, 2107-2115, 1993. 